\title{
Perhitungan Beban Refrigerasi terhadap Hasil Tangkapan pada KM. Harapan Sri Jaya Juwana, Pati, Jawa Tengah
}

\author{
Mardiyono*, Hilman Fadillah \\ Program Studi Permesinan Perikanan, Sekolah Tinggi Perikanan \\ Jl. AUP Pasar Minggu, Jakarta Selatan \\ *E-mail: mardiyono@kkp.go.id
}

\begin{abstract}
Abstrak
Beban refrigerasi pada ruang pembekuan dan ruang palkah di KM. Harapan Sri Jaya terdiri dari beban produk dan beban non produk. Pada ruang pembekuan, beban kalor yang harus ditanggung berasal dari beban produk, beban infiltrasi dan beban transmisi. Pada ruang palkah beban kalor yang harus ditanggung berasal dari beban infiltrasi, beban transmisi dan beban internal. Beban keseluruhan yang harus ditanggung oleh ruang pembekuan dan ruang palkah adalah penjumlahan dari beban di ruang pembekuan dan ruang palkah. Besarnya beban tersebut adalah $56 \mathrm{~kW}$. Faktor keamanan dalam perhitungan beban kalor adalah sebesar 15\% sehingga besarnya beban kalor yang ada di ruang pembekuan dan ruang palkah adalah sebesar $56 \mathrm{~kW}+(15 \%$ x 8,92 kW $)=56 \mathrm{~kW}+8,92 \mathrm{~kW}=68.4 \mathrm{~kW}$. Diketahui total beban kalor refrigerasi adalah sebesar $68,4 \mathrm{~kW}$ dan daya kompresor yang penulis ketahui pada spesifikasi yaitu $29,84 \mathrm{~kW}$ jika 3 kompresor dinyalakan secara bersamaan maka akan menghasilkan daya $(29,84 \mathrm{~kW}$ x $3=89,52 \mathrm{~kW})$. Dengan demikian dapat diketahui masing - masing kompresor menerima beban kalor sebesar 22,84 kW dimana $(68,4$ $\mathrm{kW}: 3$ unit kompresor $=22,84 \mathrm{~kW}$ ). Maka persentase dari perbandingan beban kalor refrigerasi terhadap daya motor penggerak kompresor adalah $76 \%$.
\end{abstract}

Diterima: 06-02-2020; Direvisi: 02-04-2020; Dipublikasi: 28-12-2020

Kata kunci: beban refrigerasi; komponen refrigerasi; pembekuan; palkah

\begin{abstract}
Refrigeration load in the freezing room and the space of fish hold in KM. Harapan Sri Jaya consist of product load and non products load. In freezing room, the heating load to be borne comes from product load, infiltration load and transmission load. In fish hold space heat load that must be borne derived from infiltration load, load transmission and internal loads. The overall load to be borne by the freezing room and fish hold is the sum of the loads in freezing room and fish hold. The magnitude of the load is $56 \mathrm{~kW}$. The safety factor in the calculation of the heat load is $15 \%$ so that the total heat load in the freezing room and fish hold space is $56 \mathrm{~kW}+(15 \% \times 8.92 \mathrm{~kW})=56 \mathrm{~kW}+8.92 \mathrm{~kW}=$ $68.4 \mathrm{~kW}$. It is known that total refrigeration heat load is $68,4 \mathrm{~kW}$ and compressor power which writer know in specification is $29,84 \mathrm{~kW}$, if 3 units compressor is switched simultaneously it will produce power $(29,84 \mathrm{~kW} \times 3$ units $=89,52 \mathrm{~kW})$. Thus it is known that each compressor receives a heat load of $22.84 \mathrm{~kW}$ where $(68.4 \mathrm{~kW}: 3 \mathrm{units}$ compressors $=22.84 \mathrm{~kW}$ ). Then the percentage of the ratio of the refrigeration heat load to the electro motor power of the compressor is $76 \%$.
\end{abstract}

Keywords: Refrigeration load; refrigeration components; freezing; fish lod

\section{Pendahuluan}

Negara Indonesia merupakan negara maritim yang terbesar di dunia dengan 2/3 wilayahnya merupakan lautan yang membentang dari ujung utara Pulau Sumatera sampai ke ujung selatan Papua. Hal ini menjadikan mayoritas penduduk yang berada di daerah pesisir pantai bermata pencaharian sebagai nelayan, pengolah ikan dan pembudidaya ikan serta pedagang ikan. Agar memperoleh hasil tangkapan ikan yang banyak dengan mutu hasil tangkapan yang terjamin maka perlu dilakukan perluasan daerah operasi penangkapan ikan (fishing ground) sehingga membutuhkan dukungan suatu sistem pendingin agar kualitas hasil tangkapan ikan terjaga [1]. Sehingga tidak hanya mendapatkan ikan hasil tangkapan yang banyak namun juga berkualitas. Hal ini akan berpengaruh terhadap nilai jual ikan yang tinggi. Pada umumnya, teknik refrigerasi yang digunakan pada kapal penangkap ikan ialah teknik refrigerasi mekanik, dimana teknik refrigrasi mekanik ini menggunakan tenaga listrik untuk menggerakkan motor penggeraknya untuk operasional sistem refrigerasi, sehingga dapat mengawetkan ikan dengan cara pembekuan (freezing) dan penyimpanan ikan di ruang beku (fish hold) [2,3]. Sistem 
refrigerasi ini memanfaatkan sifat-sifat panas (thermal) dari bahan pendingin (refrigrant) selagi ia berubah dari keadaan cairan menjadi gas/uap dan sebaliknya [4].

Prinsip kerja dari sistem refrigerasi yaitu menurunkan suhu hasil perikanan (termasuk pada titik pusat geometri badan ikan) mencapai sekitar $0^{\circ} \mathrm{C}$. Pada suhu rendah aktifitas mikroba, enzim, maupun reaksi kimia dapat ditekan sehingga proses pembusukan dapat diperlambat. Pembekuan maupun pendinginan bertujuan untuk menghambat kegiatan mikro organisme dan proses kimia serta fisik lainnya yang dapat mempengaruhi mutu kesegaran produk perikanan [5].

Tujuan penelitian ini adalah untuk mengetahui beban refrigerasi terhadap hasil tangkapan terutama dalam mempertahankan mutu produk ikan dan untuk mengetahui kapasitas sistem refrigerasi yang ada sehingga bisa menjadi rekomendasi untuk memaksimalkan operasi penangkapan ikan oleh para nelayan. Sistem refrigerasi dikapal digunakan untuk beberapa keperluan diantaranya: ruang pembekuan (freezer), ruang penyimpanan beku (fish hold), ruang penyimpan sayur dan juga untuk pendingin air tawar[6]. Untuk ruang pembekuan menggunakan tipe contact plate freezer, sedangkan untuk keperluan ruang penyimpanan beku (fish hold) menggunakan tipe air blast freezer yaitu dua unit evaporator yang dilengkapi dengan kipas sedangkan untuk ruang penyimpan sayur hanya menggunakan evaporator yang menggunakan pipa galvanis tanpa dilengkapi dengan kipas [7].

Kompresor yang digunakan adalah jenis torak satu tingkat dengan 3 unit kompresor yang seluruhnya merupakan jenis open type. Kompresor dihubungan dengan van belt ke motor penggerak. Kompresor ini bekerja secara bergantian sesuai dengan kebutuhan beban refrigerasi. Pengoperasian unit refrigerasi harus sesuai dengan prosedur yang berlaku. Hal ini bertujuan untuk mengurangi kerusakan dan mengoptimalkan kinerja dari unit refrigerasi.

\section{Material dan Metodologi}

\subsection{Waktu dan Tempat}

Penelitian dilaksanakan selama 6 (enam) bulan yaitu mulai tanggal 1 November 2016 sampai dengan 5 Mei 2017 di KM. Harapan Srijaya, Juwana-Pati, Jawa Tengah.

\subsection{Studi Literatur dan Lapangan}

Studi Literatur digunakan untuk memperoleh informasi - informasi yang relevan terkait dalam penyelesaian penelitian ini. Informasi-informasi diperoleh dari buku, jurnal, internet, dan penelitian sebelumnya tentang sistem pendingin Studi Lapangan digunakan untuk memperoleh Informasi - informasi yang berkaitan dengan penelitian di lapangan, sehingga dalam studi ini nantinya akan memperoleh data-data di lapangan yang kemudian diolah.

\subsection{Pengumpulan Data}

Pengumpulan data dilakukan untuk memperoleh data-data pendukung dalam mengerjakan penelitian ini. Data diperoleh dengan pengumpulan data dilapangan dengan cara pengukuran, pengamatan langsung dan wawancara dengan pihak terkait. data yang diperlukan adalah: Ukuran utama kapal, volume palka kapal, konstruksi palka kapal, operasional kapal, spesifikasi komponen sistem refrigerasi, layout desain sistem refrigerasi pada kapal.

\subsection{Metode Analisis Data}

Metode Analisis Data dalam penelitian ini menggunakan, 1) Analisis deskriptif (kualitatitf), yaitu dengan mengamati kemudian membuat penjelasan secara sistematis, faktual dan akurat diatas kapal. 2) Analisis kuantitatif, yaitu menganalisis 
data yang berupa angka atau numerik secara teoritis maupun praktis dilapangan yang ditunjukkan oleh alat ukur yang ada pada pesawat.

a) Tahap Pendinginan

$\mathrm{Q}_{\mathrm{lb}}=\mathrm{m} \times(\mathrm{Tl}-\mathrm{Tb}) \times \mathrm{c}$

dimana: $\quad$ Qlb $=$ Banyaknya beban refrigerasi $(\mathrm{kJ})$

$\mathrm{m} \quad=$ Berat produk $(\mathrm{kg})$

$\mathrm{T} 1=$ Temperatur awal $\left({ }^{\circ} \mathrm{C}\right.$ atau $\left.{ }^{\circ} \mathrm{K}\right)$

$\mathrm{Tb}=$ Temperatur akhir $\left({ }^{\circ} \mathrm{C}\right.$ atau $\left.{ }^{\circ} \mathrm{K}\right)$

c $\quad=$ Panas spesifik ikan di atas titik beku $\left(\mathrm{kJ} / \mathrm{kg}^{0} \mathrm{~K}\right)$

b) Tahap Pembekuan

$\mathrm{Q}_{\mathrm{b}}=\mathrm{m} \times \mathrm{h}_{\mathrm{if}}$

c) Tahap Pembekuan Lanjut

$\mathrm{Q}_{\mathrm{bp}}=\mathrm{m} \times\left(\mathrm{T}_{\mathrm{b}}-\mathrm{T}_{\mathrm{p}}\right) \times \mathrm{ci}$

dimana: $\quad h_{\text {if }}=$ Panas laten pembekuan $(\mathrm{kJ} / \mathrm{kg})$

d) Total panas beban refrigerasi

$\mathrm{Q}_{\mathrm{p}}=\mathrm{Q}_{\mathrm{lb}}+\mathrm{Q}_{\mathrm{b}}+\mathrm{Q}_{\mathrm{bp}}$

dimana: $c i=$ Panas spesifik ikan bawah beku $\left(\mathrm{kJ} / \mathrm{kg}^{\mathrm{O}} \mathrm{K}\right)$

e) Beban refrigerasi total

$$
\begin{aligned}
& \mathrm{q}_{\text {total }}=\mathrm{q}_{\mathrm{p}}+\left(\mathrm{q}_{\mathrm{u}}+\mathrm{q}_{\text {in }}+\mathrm{q}_{\mathrm{d}}\right) \\
& \text { dimana: } q_{p}=\text { Beban refrigerasi dari produk }(\mathrm{KW}) \\
& q_{d} \quad=\text { Beban refrigerasi dari transmisi (KW) } \\
& q_{u} \quad=\text { Beban refrigerasi dari infiltrasi }(\mathrm{KW}) \\
& q_{i n}=\text { Beban refrigerasi dari internal }(\mathrm{KW}) \\
& q_{t o t}=\text { Beban refrigerasi total }(\mathrm{KW})
\end{aligned}
$$

\section{Hasil dan pembahasan}

Beban kalor di ruang pembekuan adalah perhitungan jumlah beban kalor mulai dari produk yang didinginkan dengan faktor faktor yang mempengaruhi proses pendinginan dalan ruang pembekuan.

\subsection{Beban Produk}

Produk yang didinginkan berupa ikan yang mempunyai temperature rata - rata sebesar $28^{\circ} \mathrm{C}$ Tangkapan terbesar terdapat pada satu bulan terakhir dengan sampel ikan Layang (Decapterus sp.) dengan hasil tangkapan sebanyak $6.757 \mathrm{Kg}$, 
dengan waktu pembekuan $12 \mathrm{jam}$. Temperatur Ikan pada waktu tertangkap adalah antara $25^{\circ} \mathrm{C}-28^{\circ} \mathrm{C}$ sehingga dapat diambil rata - rata temperatur ikan adalah sebesar $27^{\circ} \mathrm{C}$. Untuk menghitung beban panas ikan ada tiga tahapan penurunan temperatur pada saat pembekuan produk [8].

Penurunan temperatur ikan adalah 642.914,24 kJ, dengan tahap pembekuan sebesar 1.595.567 kJ. Selanjutnya membekukan ikan lebih lanjut, dari temperatur beku $T_{b}$ mencapai temperatur penyimpanan beku $T_{p}$. Panas yang harus dienyahkan adalah panas sensible bawah beku dari temperatur beku $T_{b}$ ke arah temperatur penyimpanan beku $T_{p}$ sebesar 183.256,91 kJ, jadi panas beban refrigerasi dari produk adalah 2.421.738,15 kJ. Hasil perhitungan total jumlah proses turunya panas yaitu $932.308,325 \mathrm{~kJ}$ atau dikonversikan menjadi $56,1 \mathrm{~kW}$

\subsection{Perhitungan Beban Non Produk}

Beban dari pertukaran udara yang terjadi akibat dari pembukaan pintu freezer dan fish hold sehigga udara masuk ke dalam ruangan tersebut. Dengan mengetahui volume dan ruang tersebut maka besarnya beban dari pertukaran panas = 493,51315 $\mathrm{ft}^{3}$. Nilai pergantian udara per 24 jam dari volume 493,51315 $\mathrm{ft}^{3}$ dengan pertukaran udara 24 jam di bawah 32 ${ }^{\circ} \mathrm{F}$ adalah 20,252 . Temperatur rata - rata dalam freezer dalam satu trip yaitu $-14,33{ }^{\circ} \mathrm{C}$ maka $=\{9 / 5 \times(-14,33)+32\}=$ $6,21^{\circ} \mathrm{F}$. Maka faktor pertukaran adalah 1,38 .

\subsection{Total Keseluruhan Beban Refrigerasi}

Hasil perhitungan untuk mengetahui beban refrigerasi total adalah dengan menjumlahkan beban refrigerasi $68.4 \mathrm{~kW}$

\subsection{Persentase Beban Kalor Refrigerasi Terhadap Kompresor}

Perbandingan antara daya kompresor yang dihasilkan selama beroperasi terhadap beban kalor refrigerasi dapat dihitung dengan hasil perhitungan keseluruhan beban kalor refrigerasi dibanding dengan daya kompresor[9, 10]. Jika total beban kalor refrigerasi adalah sebesar $68,4 \mathrm{~kW}$ dan daya kompresor yang penulis ketahui pada spesifikasi yaitu 29,84 kW jika 3 kompresor dinyalakan secara bersamaan maka akan menghasilkan daya $(29,84 \mathrm{~kW}$ x $3=89,52 \mathrm{~kW})$. Dengan demikian dapat diketahui masing - masing kompresor menerima beban kalor sebesar 22,84 kW dimana $(68,4 \mathrm{~kW}: 3$ kompresor $=$ $22,84 \mathrm{~kW})$. Maka persentase dari perbandingan beban kalor refrigerasi terhadap daya kompresor adalah $76 \%$.

\subsection{Mempertahankan Suhu Ikan}

Penyimpanan beku sebaiknya tidak digunakan untuk menyimpan ikan [11], akan tetapi merupakan proses pembekuan lanjutan setelah ikan mengalami proses pembekuan terlebih dahulu di dalam freezer [12]. Penyimpanan ikan secara langsung dalam cold storage, akan menyebabkan timbulnya kerusakan pada tekstur daging ikan; sehingga pada saat thawing dilakukan, tekstur daging ikan tersebut akan menjadi lebih lembek. Ikan yang disimpan beku, dapat di simpan hingga 7 bulan tanpa perubahan yang berarti. Ikan yang berlemak tinggi harus disimpan beku dalam kondisi suhu yang sangat rendah, untuk mencegah timbulnya proses oksidasi lemak yang berlebihan yang mengarah pada kerusakan mutu $[13,14,15]$. Dengan kisaran suhu penyimpanan dalam palkah sekitar $-7,81^{\circ} \mathrm{C}$.

\section{Kesimpulan}

Unit sistem refrigerasi yang terdapat pada KM. Harapan Sri Jaya terdiri dari komponen pokok, komponen bantu dan komponen kontrol. Komponen pokok terdiri dari Kompresor, kondensor, receiver, katup ekspansi, dan evaporator. Sedangkan pada komponen bantu terdiri dari, akumulator, sight glass, oil separator, filter and dryer, HPC, LPC, dan OPC. 
Komponen tersebut bekerja dengan cara mensirkulasikan refrigerant sehingga terjadilah proses penyerapan kalor pada evaporator. Sumber beban kalor yang diserap oleh evaporator pada ruang pembekuan adalah $68,4 \mathrm{~kJ}$ atau jika di konversikan menjadi kW adalah 68,4 kW. Jadi total beban kalor dari $6.757 \mathrm{Kg}$ ikan layang pada tanggal 14 Februari 2017 dalam satu kali setting di KM. Harapan Sri Jaya yang diserap pada evaporator adalah sebesar $68,4 \mathrm{~kW}$. Diketahui total beban kalor refrigerasi adalah sebesar $68,4 \mathrm{~kW}$ dan daya kompresor yang dihidupkan sebanyak 3 buah kompresor dengan daya yang sama yaitu $29,84 \mathrm{~kW}(29,84 \mathrm{~kW}$ x $3=89,52 \mathrm{~kW})$.

\section{Ucapan terima kasih}

Terima kasih kepada Ketua Sekolah Tinggi Perikanan dan seluruh Crew KM. Harapan Srijaya, atas bantuan dan kesempatan untuk dapat penelitian dan pengambilan data.

\section{Daftar Pustaka}

[1] Slamet, A., Putro, W.D., 2017, "Rekayasa Model Mesin Pendingin Ikan Tangkapan Nelayan Dengan Memanfaatkan Kelebihan Daya Mesin Diesel Penggerak Propeler Perahu,” Jurnal Rekayasa Mesin, Vol. 12 No. 3.

[2] Handoko, H., “ Lemari Es “ Jakarta. 1981.

[3] Karyanto, E., Teknik Mesin Pendingin Volume 2. Restu Agung. Jakarta. 2004.

[4] Ilyas S., Teknologi Refrigerasi Hasil Perikanan. Jilid II. Teknik Pendinginan Ikan. CV Paripurna. Jakarta. 1983

[5] Moeljanto, Pengawetan dan Pengolahan Hasil Perikanan. Penebar Swadaya. Jakarta, 1992

[6] Riyadi, Mamat, Analisa Teknis dan Ekonomis Penggunaan Sistem Pendiingin Refrigerated Sea Water (RSW) pada Kapal Nelayan Tradisional. 2016.

[7] Jordan, Priester, Refrigeration and Air Conditioning volume 2. Prentice-Hall. India. 1981

[8] Sumanto, Dasar - Dasar Mesin Pendingin. Andi. Yogyakarta. 2004

[9] Stoecker, WF., Jones JW., Refrigerasi dan Pengkondisian Udara, Erlangga, Jakarta 1996

[10] Dossat, J Roy. Principles of Refrigeration : S I Version Edition 2. Wiley, Newyork. 1981

[11] Hastrini R., Rosyid A., Riyadi. P.H., Analisis penanganan (Handling) Hasil Tangkapan Kapal Purse Seine yang di daratkan di Pelabuhan Perikanan Pantai (PPP) Bajomulyo Kabupaten Pati. 2017

[12] Arismunandar, W., Penyegaran Udara. Pradnya Pramita. Jakarta. 2005

[13] Hartanto, B., Diktat Mata Kuliah Mesin Pendingin. Balai Pengembangan Penangkapan Ikan. Semarang. 1983

[14] Junianto, Teknik Penanganan Ikan. Penebar Swadaya. Bandung. 2003.

[15] Muis, Gritis Al-Hasbi Mochamad, Analisa Unjuk Kerja Desain Sistem Refrigerasi Kompresi Uap pada Kapal Ikan Ukuran 5 GT di Wilayah Rembang. 2016 